\title{
MAXIMIZING ENERGY SAVINGS ATTAINABLE BY DYNAMIC INTENSIFICATION OF BINARY DISTILLATION
}

\author{
LINGQING YAN ${ }^{\mathrm{a}}$, THOMAS F. EDGAR ${ }^{\mathrm{a}}$, \\ MICHAEL BALDEA ${ }^{\mathrm{a}, \mathrm{b}^{*}}$
}

\begin{abstract}
Dynamic intensification of distillation columns has shown significant promise in achieving energy savings with minimal investment in new equipment. Conceptually, it entails making a desired product as a blend of two auxiliary products (one with higher purity, the other with lower purity, but both having lower energy consumption). Practically, dynamic intensification means periodically switching between two operating states corresponding to the aforementioned products. Past work has relied on ad-hoc choices of auxiliary products. In this paper, we introduce a new optimization framework for selecting auxiliary products for dynamic intensification. An extensive case study concerning the separation of a methanol/propanol mixture is then presented. We show that optimizing the choice of auxiliary products can lead to significant energy savings (more than $3.6 \%$ compared to a column operated at steady state) derived from dynamic intensification.
\end{abstract}

Keywords: process intensification; dynamic intensification; distillation; energy efficiency, optimization

\section{INTRODUCTION}

The chemical industry turns raw materials into value-added products via physical and/or chemical transformations. In most circumstances, the feedstock of chemical plants contains (traces of) impurities. Moreover, most chemical reactors are not designed for complete conversion, and many chemical

\footnotetext{
a McKetta Dept. of Chemical Engineering, The University of Texas at Austin, Austin, TX 78712, USA

b Institute for Computational Engineering and Sciences, The University of Texas at Austin, Austin, TX 78712, USA

*Corresponding author: mbaldea@che.utexas.edu
} 
reactions produce a (set of) desired product(s) and (several) undesired by product(s). As a consequence, chemical plants comprise reaction and separation units, interconnected via material and energy recycle streams [1]. Separation units account for a significant portion of the capital and operating cost of a chemical plant, with distillation being the dominant approach for separating liquid mixtures. In the United States alone, it was estimated that there are about 40,000 distillation columns in operation, which handle $90-95 \%$ of total separation needs [2]. Distillation columns are quite flexible and robust in dealing with fluctuations in feed quality and product constraints [3]. However, distillation is a thermal process that exploits the difference in volatility between the components of the mixture. This requires that the mixture to be separated be brought to a boiling state, which, in turn, entails a significant energy input. The theoretical energy use of distillation columns is driven by the nature of the mixture, and increases as the throughput of the system increases. The energy demand (typically described in terms of the amount of steam supplied to the reboiler) of columns used in industry is further increased by inefficiencies related to heat loss, heat transfer, etc. Overall thermal efficiencies as low as $10 \%$ may be encountered in practice [4].

Significant research and engineering efforts have been directed at lowering the energy consumption of distillation columns. In the design realm, we recall, e.g., thermal integration concepts (whereby a heat source - typically a condenser - within a column or a distillation train is used to meet heat demand in a sink - typically a reboiler), intensification (such as the case of dividing wall columns, whereby the function of two or more distillation columns is combined in a single shell, compartmented by a septum/wall) $[5,6,7]$.

In the operations area, work has focused on imposing cyclic operating patterns that segregate liquid and vapor traffic in the column, with the purpose of minimizing energy inefficiencies associated with (re)mixing. The advent of these ideas can be traced back to the 1960s [8], and research continues to date. The implementation of cyclic distillation concepts can lead to significant energy savings (compared to a conventional column of the same capacity) [9] but entails major equipment changes. Separating the movement of the vapor and liquid phases requires special trays and control strategies that can manage frequent (occurring every minute or faster) flow redirection. The capital expenditure is significant for new projects, and can be prohibitive for retrofits.

In several recent publications [10,11], we introduced dynamic process intensification (DPI) as a novel operational approach for lowering energy use in distillation columns. DPI exploits the nonlinearities inherently present in the static behavior of distillation columns to create periodic, dynamic operating patterns that produce the same output (in terms of time-averaged flow rates and purities of the products) as an equivalent conventional column, 
but with lower energy consumption. Importantly, DPI relies on existing distillation hardware and can therefore be deployed on a significant number of columns already in operation.

Our early work in DPI focused on demonstrating the concept empirically; in this paper, we propose a rigorous optimization framework for defining the maximum energy savings attainable by DPI. The paper is organized as follows: in the next section, we introduce the DPI framework and the underlying physics. Next, we define the optimization framework for computing the maximum achievable energy savings. A case study, focused on the separation of an equimolar methanol/propanol mixture is presented, demonstrating considerable energy savings compared to the empirical case. Finally, we draw conclusions and propose potential directions for future work.

\section{DYNAMIC INTENSIFICATION OF BINARY DISTILLATION: CONCEPT}

We begin by defining dynamic process intensification (DPI) in the general case, as any "changes to the dynamics, operation strategy, and/or control of a process that lead to a substantially more efficient processing path." [11] This general statement was translated to the intensification of binary distillation columns by exploiting their intrinsically nonlinear behavior. Specifically, early work by Jacobsen and Skogestad [12] (later confirmed experimentally by Koggesbol et al. [13]) revealed an economically interesting output multiplicity. This consists of a nonlinear steady-state characteristic whereby the same reboiler duty $Q_{B}$ (manipulated input and significant contributor to column operating cost) could lead to two different values of the distillate purity $\mathrm{y}_{\mathrm{d}}$ (controlled variable/ output), as shown in Figure 1.

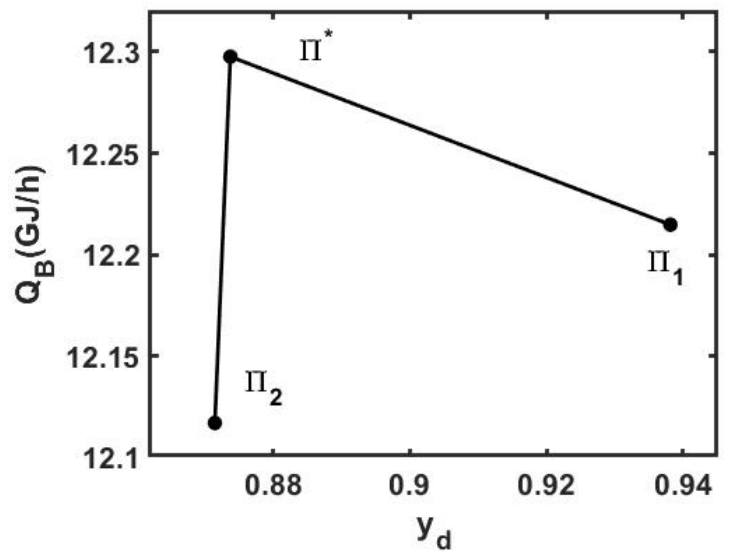

Figure 1. Nonlinear non-monotonic representation of target and two auxiliary products in terms of distillate purity and reboiler duty 
This observation served as the basis for formulating the DPI paradigm for binary distillation columns in terms of producing an energy-intensive (i.e., having high reboiler duty $\mathrm{Q}_{\mathrm{B}}{ }^{*}$ ) product $\Pi^{*}$, with target purity $\mathrm{y}_{\mathrm{d}}{ }^{*}$, as a mixture of two auxiliary products $\Pi_{1}$ and $\Pi_{2}$, having purities $y_{d, 1}$ (higher than the target purity) and, respectively, purity $\mathrm{y}_{\mathrm{d}, 2}$ (lower than the target purity). The reboiler duties corresponding to the auxiliary products are, respectively, $Q_{B, 1}$ and $Q_{B, 2}$. Importantly, both $\mathrm{Q}_{\mathrm{B}, 1}$ and $\mathrm{Q}_{\mathrm{B}, 2}$ are lower than $\mathrm{Q}_{\mathrm{B}}{ }^{*}$ and, as a consequence, the mixture of the two auxiliary products, chosen in the appropriate proportion, can have the same average purity as target purity $\mathrm{yd}_{\mathrm{d}}{ }^{*}$, but lower average energy consumption than $\mathrm{Q}_{\mathrm{B}}{ }^{*}$.

Of critical importance here is the split coefficient $\alpha$, defined such that:

$$
\begin{gathered}
\alpha \text { Product Flow Rate } \Pi_{1}+(1-\alpha) \text { Product Flow Rate } \Pi_{2}= \\
\text { Product Flow Rate } \Pi^{*} \\
\alpha \text { Product Purity } \Pi_{1}+(1-\alpha) \text { Product Purity } \Pi_{2}= \\
\text { Product Purity } \Pi^{*}
\end{gathered}
$$

That is, $\alpha$ is weighting the product qualities of the auxiliary products, such that the weighted average of the respective values is equal to the desired/target value for the desired product $\Pi^{*}$. From a practical perspective, the implementation of this concept entails operating a single distillation column in a transient, periodic fashion, switching between making products $\Pi_{1}$ and $\Pi_{2}$ with a frequency dictated by $\alpha$. The desired product $\Pi^{*}$ is obtained as a time-averaged mixture of the auxiliary products. Naturally, in practice, this requires the installation of holding tanks for the distillate and bottoms products of the distillation column, where the high purity and low purity auxiliary products are mixed and the "time averaging" occurs.

The DPI concept described above is not applicable immediately to binary distillation columns due to an additional complication. Conditions (1) cannot be simultaneously met by altering only the boilup rate. First, considering, e.g., the case of the distillate product, it is intuitive that, as the distillate purity increases, its flow rate will drop. In turn - based on the column overall and component material balances - the bottoms flow rate will increase, and the purity of the bottoms product (in terms of the heavy component) will drop to accommodate the decrease in the amount of light component that leaves the column as distillate.

In our previous work, we have resolved this problem by defining the auxiliary product in terms of broader operating states, characterized as a function of the values of multiple manipulated variables. In addition to boilup rate, these include, e.g., reflux rate, column pressure. In this manner, we 
demonstrated that, with the appropriate choice of the split coefficient and auxiliary operating states, a periodically operated distillation column can meet, on average over time, all the product specifications (purity, flow rate) of a conventional, steady-state column, but with lower energy consumption (defined in terms of reboiler duty or the sum of reboiler and condenser duties).

\section{OPTIMIZING AUXILIARY PRODUCTS FOR DYNAMIC INTENSIFICATION}

Our previous work relied on ad-hoc choices of the auxiliary products and related operating states. These were largely based on empirical exploration, via steady-state simulation, of the static nonlinear response of a column to changes in the manipulated variables frequently used in practice. In this section, we aim to set this exploration on a rigorous basis. Below, we describe an optimization problem formulation that captures the search for the optimal auxiliary operating states and split coefficient for dynamic intensification.

The inputs of the problem are as follows: we assume that the parameters of the binary feed mixture and target properties of the distillate and bottoms products (flow rate, composition) are known, and that the desired separation is feasible with a finite number of theoretical stages. Further, we assume that a steady-state model of the column is available, reflecting the material and energy balances, as well as relevant constitutive relations (e.g., phase equilibria) of the column operating at the respective state. Finally, we state that the choice of $n$ manipulated variables $\left(M V_{i}, i=1, \ldots, n\right)$ to be used in imposing periodic operation is fixed a priori (that is, the optimization procedure will not select which column inputs to manipulate; rather, it will set their values within known upper and lower bounds). Implicitly, we assume that a control scheme can be designed to impose the periodic transitions between the two auxiliary operating states.

Under these circumstances, the goal of solving the optimization problem is to identify the values of the split coefficient and the values $M V_{i, 1}$ and $M V_{i, 2}$ of the manipulated variables at each of the two operating states, such that the weighted average energy consumption of the column $\alpha \mathrm{Q}_{\mathrm{B}, 1}+(1-\alpha) \mathrm{Q}_{\mathrm{B}, 2}$ is lower than that of the aforementioned steady-state design. The constraints of the problem include, i) ensuring that flow rate and quality constraints (1) are met for distillate and bottoms, ii) that the manipulated variables are within their bounds, and iii) that the material and energy balance equations are satisfied at both auxiliary operating states.

Thus, the problem statement is as follows: 


$$
\min _{\alpha, M V_{i, 1}, M V_{i, 2}} \alpha \mathrm{Q}_{\mathrm{B}, 1}+(1-\alpha) \mathrm{Q}_{\mathrm{B}, 2}
$$

s.t.

$$
\begin{aligned}
& \text { quality and flow constraints (1) } \\
& M V_{i, \min } \leq M V_{i} \leq M V_{i, \max } \\
& \alpha_{\min } \leq \alpha \leq \alpha \max \\
& \mathrm{F}\left(M V_{i, 1}\right)=0 \\
& \mathrm{~F}\left(M V_{i, 2}\right)=0
\end{aligned}
$$

where $F\left(M V_{i, 1}\right)=0$ and $F\left(M V_{i, 2}\right)=0$ reflect the constraint that the material and energy balance equations of the column must be satisfied at both auxiliary operating states.

We note that problem (2) is nonlinear and non-convex, and multiple local minima are to be expected. One of these minima is in fact the original set of operating conditions of the column, where $M V_{i, 1}=M V_{i, 2}=M V_{i}^{*}$. In order to steer the optimization solver away from this trivial solution, additional constraints should be included; these can be of the form

$$
\begin{aligned}
& M V_{i, \min , 1} \leq M V_{i, 1} \leq M V_{i, \max , 1} \\
& M V_{i, \min , 2} \leq M V_{i, 2} \leq M V_{i, \max , 2} \\
& M V_{i, \text { max }, 1} \leq M V_{i, \text { min }, 2}
\end{aligned}
$$

\section{CASE STUDY: OPTIMAL DYNAMIC INTENSIFICATION OF A METHANOL- PROPANOL BINARY DISTILLATION COLUMN}

In this section, we build on the extensive case study of the dynamic intensification of a methanol-propanol binary distillation column, that we presented earlier [11], and identify the optimal (rather than ad-hoc) auxiliary operating states. Figure 2 shows the design and control configurations of the column and lists operating conditions under the reference steady state for the target distillate and bottoms products. The column has a total of 8 stages, including a total condenser and a reboiler, and was modeled in AspenPlus [14]. An equimolar mixture of methanol-propanol enters the column at stage 4 as a saturated liquid at 1.03 bar. The reference steady state operating pressure of the column is $1.00 \mathrm{bar}$, with $300 \mathrm{kmol} / \mathrm{h}$ reflux rate and 11.51 boilup ratio. The target distillate purity is $\mathrm{y}_{\mathrm{d}}{ }^{*}=87.37 \%$, with a distillate flow rate of $34.26 \mathrm{kmol} / \mathrm{h}$. Two blending tanks are used to reflect the needs of dynamic intensification. These tanks were not explicitly modeled and are assumed to be sufficiently large to filter fluctuations in product flow rates and compositions. Six control loops are implemented: 
- boilup ratio/rate is adjusted using steam flow rate to the reboiler

- the reflux rate is adjusted using the reflux valve

- column pressure is controlled using coolant flow rate

- the feed flow rate is controlled using the feed valve

- condensate drum and sump levels are stabilized using distillate and bottoms flow rates, respectively.

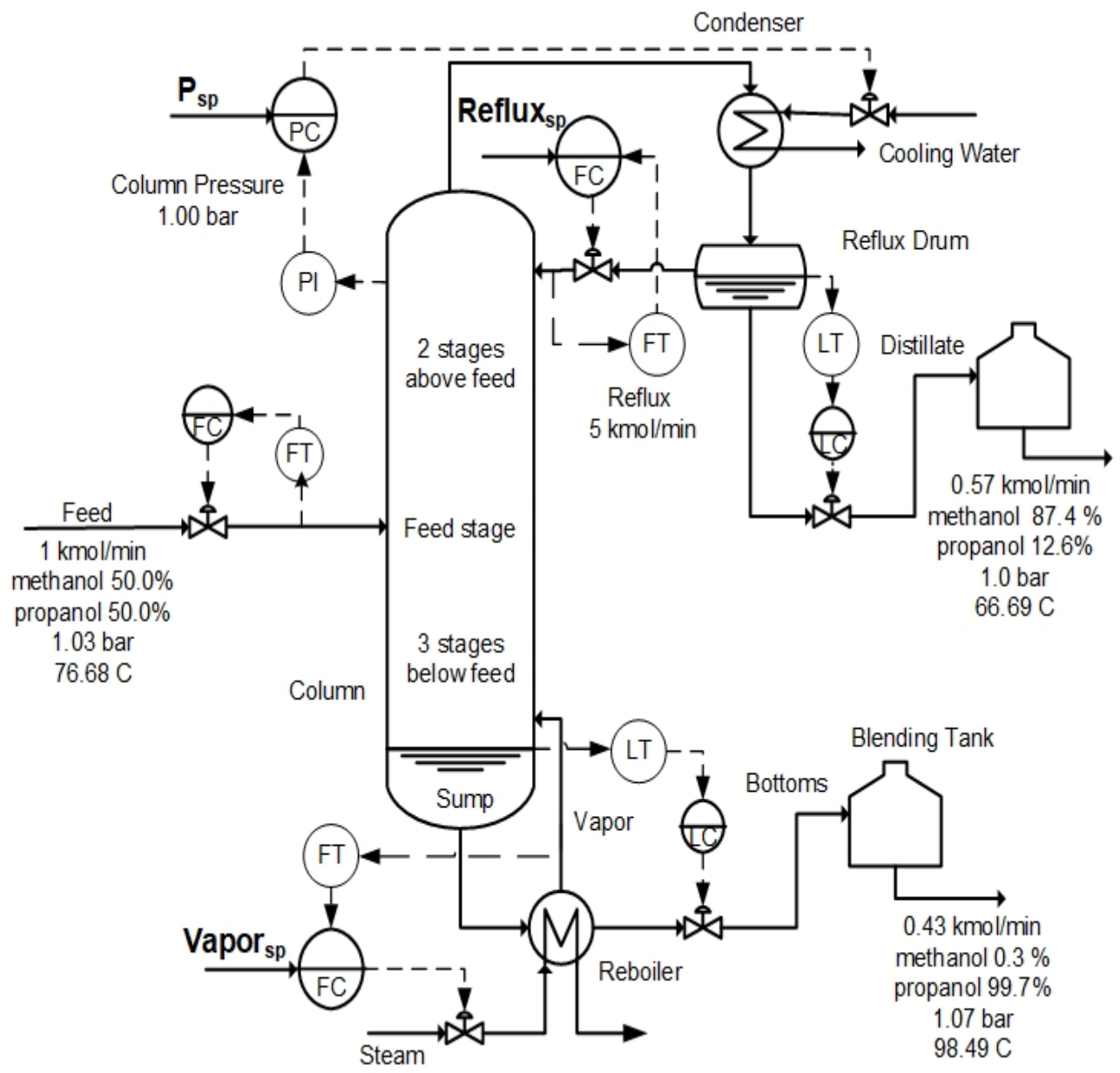

Figure 2. Schematic configuration of methanol-propanol binary column and operation conditions for reference steady state

Four manipulated variables were used to define the auxiliary operating states for dynamic intensification: reflux rate, boilup rate, column pressure and feed stream pressure. Figure 3 a) shows the effect of varying reflux rate 
on reboiler duty under fixed pressure. As expected, lower reflux rates require less energy to reach same purity as in the base case, at the cost of a drop in distillate flow rate. Figure $3 \mathrm{~b}$ ) presents the influence of column pressure on reboiler duty under fixed reflux rate. Somewhat counter-intuitively, higher pressures can save energy while maintaining same purity. The reason is that increasing pressure diminishes the amount of material vaporized.

Figure 4 shows that the pressure of saturated liquid feed has a similar effect on reducing reboiler duty as the column pressure. At the same purity, higher feed pressure is favorable to reducing reboiler energy consumption. This is due to the characteristics of the vapor-liquid equilibrium. As pressure increases, the temperature of the feed increses and therefore less steam is required to reach same bottoms temperature, with minimal impact on separation performance.
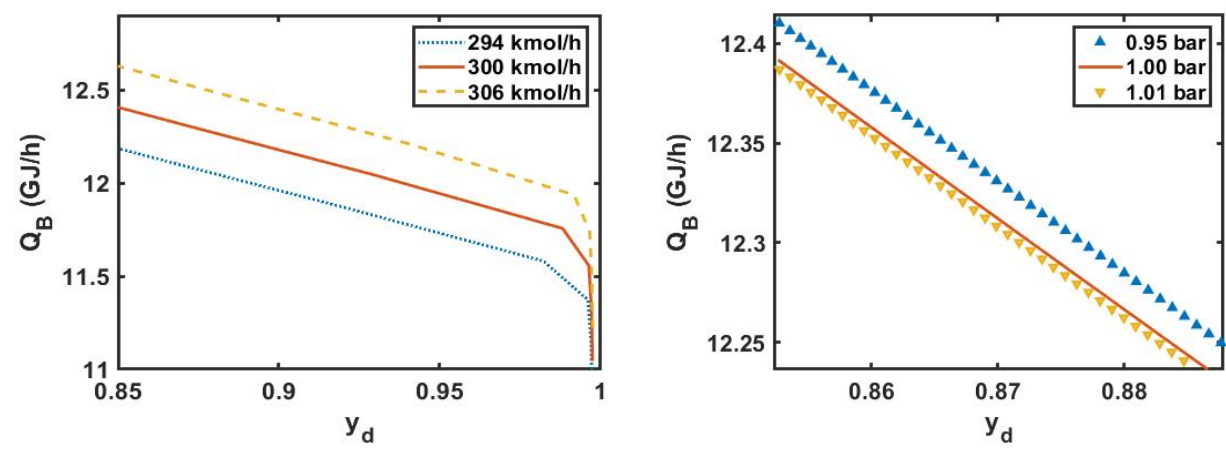

Figure 3. a) Effect of reflux rate on reboiler duty at operating pressure of 1 bar and feed pressure 1.03 bar; b) Effect of operating pressure on reboiler duty under fixed reflux rate $300 \mathrm{kmol} / \mathrm{h}$

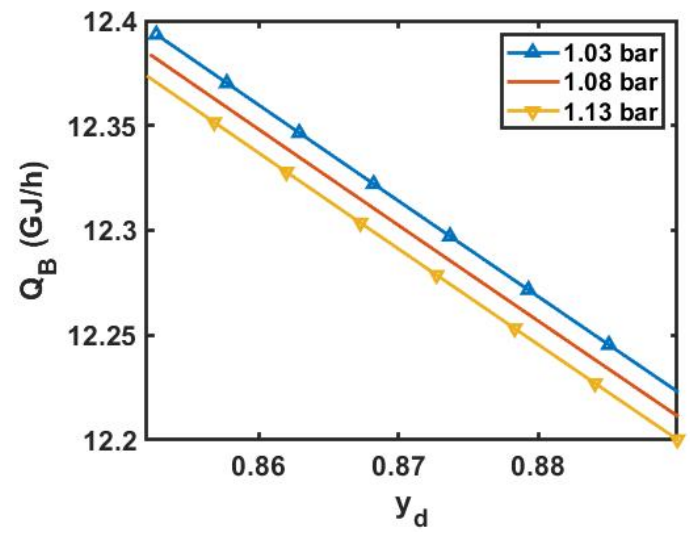

Figure 4. Effect of saturated liquid feed pressure on reboiler duty under operating pressure $1 \mathrm{bar}$ and reflux rate $300 \mathrm{kmol} / \mathrm{h}$ 
In our previous work [11], we empirically selected two auxiliary operating states, reaching $1.4 \%$ energy savings for periodic operation/dynamic intensification compared to the steady-state column. Below, we implement the optimizationbased strategy outlined above to maximize these savings.

The optimization problem includes nine decision variables: one defining the overall operation $(\alpha)$ and four for each auxiliary product/operating point, specifically column pressure $(P)$, feed pressure $\left(P_{F}\right)$, boilup ratio (Bratio) and reflux rate (Reflux).

$$
\text { Min } \alpha \mathrm{Q}_{\mathrm{B}, 1}+(1-\alpha) \mathrm{Q}_{\mathrm{B}, 2}
$$

Subject to:

$$
\begin{aligned}
& \alpha \text { Distillate }_{, 1}+(1-\alpha) \text { Distillate }_{, 2}=\text { Distillate }^{*} \\
& \alpha \mathrm{y}_{\mathrm{d}, 1}+(1-\alpha) \mathrm{y}_{\mathrm{d}, 2}=\mathrm{y}_{\mathrm{d}}{ }^{*} \\
& \mathrm{P}_{\min , 1} \leq \mathrm{P}_{1} \leq \mathrm{P}_{\max , 1} \\
& \mathrm{P}_{\mathrm{Fmin}, 1} \leq \mathrm{P}_{\mathrm{F} 1} \leq \mathrm{P}_{\mathrm{Fmax}, 1} \\
& \text { Bratio }_{\min , 1} \leq \text { Bratio }_{1} \leq \text { Bratio }_{\max , 1} \\
& \text { Reflux }_{\min , 1} \leq \text { Reflux }_{1} \leq \text { Reflux }_{\max , 1} \\
& \mathrm{P}_{\min , 2} \leq \mathrm{P}_{2} \leq \mathrm{P}_{\max _{, 2}} \\
& \mathrm{P}_{\mathrm{Fmin}, 2} \leq \mathrm{P}_{\mathrm{F} 2} \leq \mathrm{P}_{\mathrm{Fmax}, 2} \\
& \text { Bratio }_{\min , 2} \leq \text { Bratio }_{2} \leq \text { Bratio }_{\max , 2} \\
& \text { Reflux }_{\min , 2} \leq \text { Reflux }_{2} \leq \text { Reflux }_{\max , 2} \\
& \alpha_{\min } \leq \alpha \leq \alpha \max
\end{aligned}
$$

Inequality constraints reflect upper and lower bounds for the eight decision variables which are subject to change according to the different auxiliary operating points. The upper and lower bounds for the split coefficient, $\alpha$, are, respectively, 0.01 and 0.99 to guarantee at least $1 \%$ of contribution from one of the auxiliary operating points. The problem was solved for two product purities, $\mathrm{y}_{\mathrm{d}}{ }^{*}=83.37 \%$ (Table 1 lists bounds used for this case), and $\mathrm{y}_{\mathrm{d}}{ }^{*}=92.97 \%$ (Table 3 ). We note that quality and flow rate constraints were only set on the distillate product; since this is a binary column, the desired flow rate and composition of the bottoms stream are achieved implicitly by virtue of closing the material balance.

The problem was implemented and solved in AspenPlus V8.8 [14]. The flowsheet (Figure 5) uses two column units (represented as RadFrac blocks) to represent the two auxiliary operating states (which correspond to a low purity and, respectively, high purity product). The splitter blocks are used to reflect the effect of the split coefficient, while a mixer block mimics the mixing tank where the final blended product is collected. The optimization problem was solved using the DMO solver. The objective convergence tolerance was set to $1 \mathrm{e}-6$ and residual convergence tolerance to $1 \mathrm{e}-5$. To facilitate the numerical solution, the equality constraints on distillate flow rate and purity in 
(4) were reformulated as inequalities, with tolerance $5 e-4 \%$. Given a feasible initial solution, the problem could be solved in a matter of seconds on an Intel Core i7 computer with 32GB RAM running Windows 10.

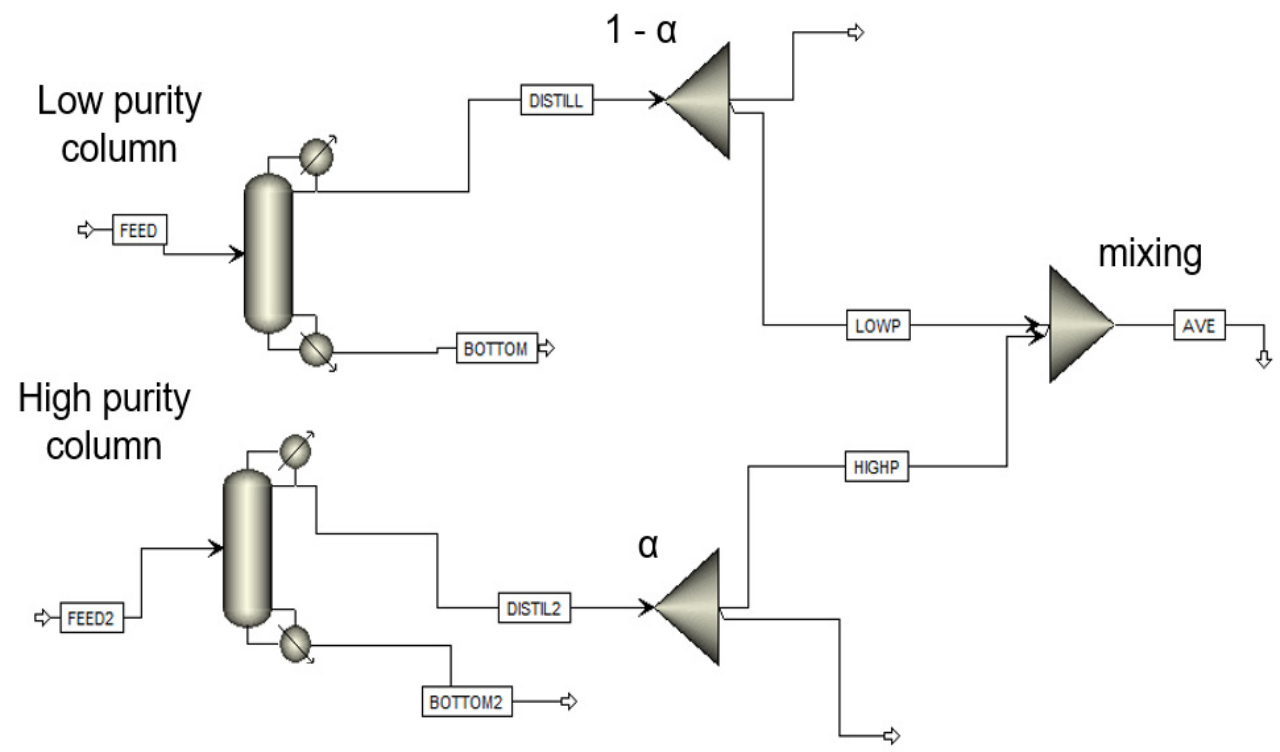

Figure 5. Aspen Plus flowsheet

Table 2 summarizes the results of the optimization calculations for $\mathrm{y}_{\mathrm{d}}{ }^{*}=83.37 \%$. The results show a potential $3.63 \%$ energy savings with no impact on product quality. The values of the manipulated variables follow the trends expected based on the discussion above (Figures 3 and 4). Both operating and feed pressure approached their upper limits and the reflux rate reached its lower limit.

The second run of the optimization problem focused on dynamic intensification at a higher purity point, $\mathrm{y}_{\mathrm{d}}{ }^{*}=92.97 \%$. Table 4 lists the corresponding optimized auxiliary operating points, based on the bounds on the manipulated variables defined in Table 3 . The optimization results show similar energy savings for the higher purity target, with closely matched average stream qualities.

A couple of remarks are in order. First, the energy savings are quite significant, and achieving them only requires changes in operating strategy with minimal hardware modifications. Second, we note that the implementation of results similar to the ones presented above in the form of a transient, periodic operation strategy was successfully demonstrated via dynamic simulation in our previous papers $[10,11]$. 
Table 1. Upper and lower bounds for decision variables, $\mathrm{yd}^{*}=83.37 \%$

\begin{tabular}{lcccc}
\hline & \multicolumn{2}{c}{ Low purity state $\Pi_{\mathbf{2}}$} & \multicolumn{2}{c}{ High purity state $\Pi_{\mathbf{1}}$} \\
\hline Decision & Lower bound & Upper bound & Lower bound & Upper bound \\
variables & 10 & 12 & 10 & 12 \\
Bratio & 287.9 & 293.9 & 300.1 & 306.1 \\
Reflux $(\mathrm{kmol} / \mathrm{h})$ & 0.96 & 1.06 & 1.001 & 1.101 \\
$\mathrm{P}$ (bar) & 0.99 & 1.09 & 1.031 & 1.131 \\
$\mathrm{P}_{\mathrm{F}}$ (bar) & & & & \\
\hline
\end{tabular}

Table 2. Optimal operating conditions, $\mathrm{yd}^{*}=83.37 \%$ with $\alpha=0.01$

\begin{tabular}{lccccc}
\hline & $\Pi^{*}$ & $\Pi_{1}$ & $\Pi_{2}$ & $\begin{array}{c}\text { Weighted } \\
\text { Ave }\end{array}$ & $\begin{array}{c}\% \\
\text { difference }\end{array}$ \\
\hline $\mathrm{y}_{\mathrm{d}}$ & 0.8737 & 0.8765 & 0.8737 & 0.8737 & -0.0005 \\
$\mathrm{~F}_{\text {methanol }}(\mathrm{kmol} / \mathrm{h})$ & 29.9339 & 29.9322 & 29.9336 & 29.9336 & -0.0010 \\
Distillate $(\mathrm{kmol} / \mathrm{h})$ & 34.2614 & 34.1489 & 34.2624 & 34.2612 & -0.0005 \\
$\mathrm{x}_{\mathrm{b}}$ & 0.9974 & 0.9974 & 0.9974 & 0.9974 & -0.0012 \\
$\mathrm{~F}_{\text {propanol }}(\mathrm{kmol} / \mathrm{h})$ & 25.6725 & 25.7833 & 25.6713 & 25.6724 & -0.0005 \\
Bottoms $(\mathrm{kmol} / \mathrm{h})$ & 25.7386 & 25.8511 & 25.7377 & 25.7388 & +0.0007 \\
$\mathrm{P}_{(\text {bar })}$ & 1 & 1.0024 & 0.9841 & & \\
$\mathrm{P}_{\mathrm{F}}(\mathrm{bar})$ & 1.03 & 1.131 & 1.09 & & \\
Bratio & 11.5102 & 11.4308 & 11.0774 & & \\
Reflux $(\mathrm{kmol} / \mathrm{h})$ & 300.0 & 300.1 & 287.9 & & \\
$\mathrm{Q}_{\mathrm{B}}(\mathrm{GJ} / \mathrm{h})$ & 12.2976 & 12.2644 & 11.8464 & 11.8506 & $\mathbf{- 3 . 6 3 4 7}$ \\
\hline
\end{tabular}

Table 3. Upper and lower bounds for decision variables, $\mathrm{yd}^{*}=92.97 \%$

\begin{tabular}{lcccc}
\hline & \multicolumn{2}{c}{ Low purity state $\Pi_{\mathbf{2}}$} & \multicolumn{2}{c}{ High purity state $\Pi_{\mathbf{1}}$} \\
\hline Decision variables & Lower bound & Upper bound & Lower bound & Upper bound \\
Bratio & 9 & 12 & 9 & 12 \\
Reflux $(\mathrm{kmol} / \mathrm{h})$ & 286 & 286.4 & 299.9 & 300.3 \\
$\mathrm{P}$ (bar) & 0.9 & 0.92 & 1.001 & 1.021 \\
$\mathrm{P}_{\mathrm{F}}$ (bar) & 0.93 & 0.95 & 1.031 & 1.051 \\
\hline
\end{tabular}


Table 4. Optimal operating conditions, $\mathrm{yd}^{*}=92.97 \%$ with $\alpha=0.01$

\begin{tabular}{lccccc}
\hline & New $\Pi^{*}$ & $\Pi_{1}$ & $\Pi_{2}$ & $\begin{array}{c}\text { Weighted } \\
\text { Ave }\end{array}$ & $\begin{array}{c}\% \\
\text { difference }\end{array}$ \\
\hline $\mathrm{y}_{\mathrm{d}}$ & 0.9297 & 0.9901 & 0.9291 & 0.9297 & +0.0004 \\
$\mathrm{~F}_{\text {methanol }}(\mathrm{kmol} / \mathrm{h})$ & 29.8769 & 29.0328 & 29.8854 & 29.8768 & -0.0002 \\
Distillate $(\mathrm{kmol} / \mathrm{h})$ & 32.1362 & 29.3218 & 32.1644 & 32.1360 & -0.0006 \\
$\mathrm{x}_{\mathrm{b}}$ & 0.9956 & 0.9672 & 0.9959 & 0.9956 & -0.0002 \\
$\mathrm{~F}_{\text {propanol }}(\mathrm{kmol} / \mathrm{h})$ & 27.7407 & 29.7110 & 27.7209 & 27.7408 & +0.0005 \\
Bottoms $(\mathrm{kmol} / \mathrm{h})$ & 27.8638 & 30.6782 & 27.8356 & 27.8640 & +0.0007 \\
$\mathrm{P}(\mathrm{bar})$ & 1.00 & 1.021 & 0.92 & & \\
$\mathrm{P}_{\mathrm{F}}(\mathrm{bar})$ & 1.03 & 1.051 & 0.95 & & \\
Bratio & 10.3947 & 9.21501 & 9.97547 & & \\
Reflux $(\mathrm{kmol} / \mathrm{h})$ & 299.5 & 299.9 & 286.0 & & \\
$\mathrm{Q}_{\mathrm{B}}(\mathrm{GJ} / \mathrm{h})$ & 12.0251 & 11.7238 & 11.5867 & 11.5881 & $\mathbf{- 3 . 6 3 4 2}$ \\
\hline
\end{tabular}

\section{CONCLUSIONS}

In this paper, we presented recent developments in maximizing the economic and energy saving benefits derived from dynamic intensification of distillation column operations. Conceptually, this entails making a desired product as a blend of two auxiliary products (one with higher purity, the other with lower purity, but both having lower energy consumption). Practically, dynamic intensification means periodically switching between two operating states corresponding to the aforementioned products. Past work has relied on ad-hoc choices of auxiliary products. Here, we formulated the problem of identifying said products as an optimization problem. An extensive case study concerning the separation of an equimolar methanol/propanol mixture demonstrated that optimizing the choice of auxiliary products can lead to significant energy savings (more than $3.6 \%$ compared to a column operated at steady state) with minimal hardware additions. We expect that these concepts can be extended to ternary separations and beyond, and the dynamic intensification of ternary columns constitutes the subject of ongoing work in our group.

\section{ACKNOWLEDGMENTS}

Funding from the U.S. Department of Energy through the RAPID Process Intensification Institute under Award DE-EE0007888-05-4 is acknowledged with gratitude.

This report was prepared as an account of work sponsored by an agency of the United States Government. Neither the United States Government nor any agency thereof, nor any of their employees, makes any warranty, express or implied, or assumes any legal liability or responsibility for the accuracy, completeness, or usefulness of any information, 
apparatus, product, or process disclosed, or represents that its use would not infringe privately owned rights. Reference herein to any specific commercial product, process, or service by trade name, trademark, manufacturer, or otherwise does not necessarily constitute or imply its endorsement, recommendation, or favoring by the United States Government or any agency thereof. The views and opinions of authors expressed herein do not necessarily state or reflect those of the United States Government or any agency thereof.

\section{DEDICATION}

Michael Baldea: with the assent of my co-authors, I dedicate this work to Professor loan Baldea. He is an academic researcher par excellence and a teacher whose pedagogic style uniquely blends scientific rigor with a healthy dose of humor. More importantly, he is the father I aspire to be.

\section{REFERENCES}

1. M. Baldea, P. Daoutidis, "Dynamics and Nonlinear Control of Integrated Process Systems", Cambridge University Press, Cambridge, UK, 2012.

2. J. L. Humphrey, Chemical Engineering Progress, 1995, 91 (10).

3. A. A. Kiss, "Advanced Distillation Technologies", John Wiley \& Sons, Ltd, Chichester, UK, 2013. https://doi.org/10.1002/9781118543702.

4. J. L. Humphrey, A. F. Seibert, R. A. Koort, Separation Technologies: Advances and Priorities, Washington DC, 1991.

5. S. S. Jogwar, M. Baldea, P. Daoutidis, Computer \& Chemical Engineering, 2010, 34 (9), 1457-1466. https://doi.org/10.1016/j.compchemeng.2010.02.005.

6. M. M. Donahue, B. J. Roach, J. J. Downs, T. Blevins, M. Baldea, R. B. Eldridge, Chemical Engineering and Process: Process Intensification, 2016, 107, 106115. https://doi.org/10.1016/j.cep.2016.05.013.

7. R. C. Pattison, A. M. Gupta, M. Baldea, AlChE Journal, 2016, 62 (3), 704-716. https://doi.org/10.1002/aic.15060.

8. M. R. Cannon, Industrial \& Engineering Chemistry, 1961, 53 (8), 629. https://doi.org/10.1021/ie50620a021.

9. B. V. Maleta, A. Shevchenko, O. Bedryk, A. A. Kiss, AlChE Journal, 2015, 61 (8), 2581-2591. https://doi.org/10.1002/aic.14827.

10. L. Yan, T. F. Edgar, M. Baldea, AIChE Journal, 2019, 65 (4), 1162-1172. https://doi.org/10.1002/aic.16506.

11. L. Yan, T. F. Edgar, M. Baldea, Industrial \& Engineering Chemistry Research, 2019, 58 (15), 5830-5837. https://doi.org/10.1021/acs.iecr.8b04852.

12. E. W. Jacobsen, S. Skogestad, AlChE Journal, 1991, 37 (4), 499-511. https://doi.org/10.1002/aic.690370404.

13. A. KoggersbøI, T. R. Andersen, J. Bagterp, S. B. Jørgensen, Computer \& Chemical Engineering, 1996, 20 (96), S835-S840. https://doi.org/10.1016/00981354(96)00147-0.

14. Aspen Technology Aspen Plus, www.aspentech.com 